Clinical Image

ISSN: 2455-8702

\title{
Bilateral Congenital Colobomas and Vitiligo in a Blind Middle Aged Female
}

Tariq Khurram ${ }^{1 \star}$, Farhangi Arezo ${ }^{2}$ and Rana Fauzia ${ }^{3}$

${ }^{1}$ Tariq, Khurram, MD, Internal Medicine, University of Florida, USA

${ }^{2}$ Farhangi, Arezo, MD, Internal Medicine, Semnan University of Medical Sciences, Iran

${ }^{3}$ Rana, Fauzia, MD, Internal Medicine, University of Florida, USA

*Corresponding author: Khurram Bilal Tariq, MD, University of Florida, Department of Internal Medicine, 653 West 8th Street, Box L 18, Jacksonville, FL 32209, Phone: 904-244-3093, E-mail: Khurram.Tariq@jax.ufl.edu

Received: June 27, 2014; Accepted: July 02, 2014; Published: July 03, 2014

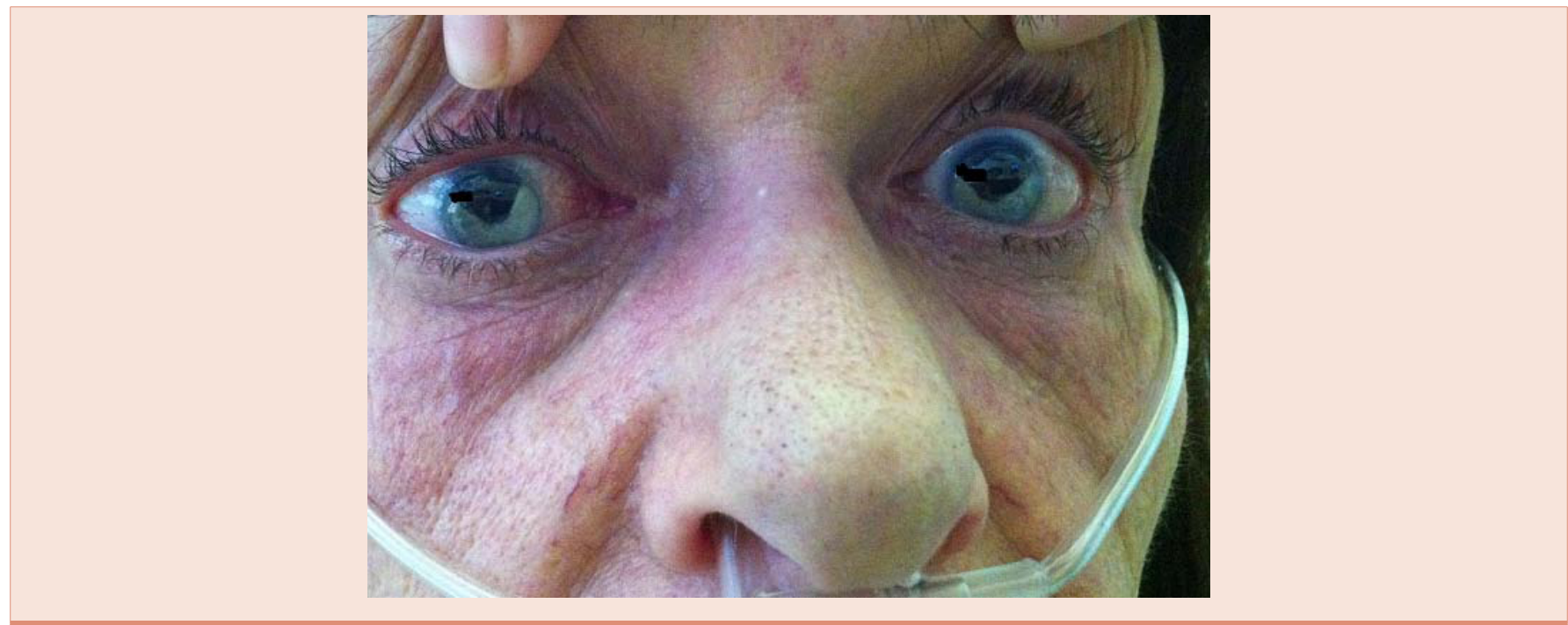

Figure 1: Bilateral Congenital Colobomas leading to blindness in this middle aged female.

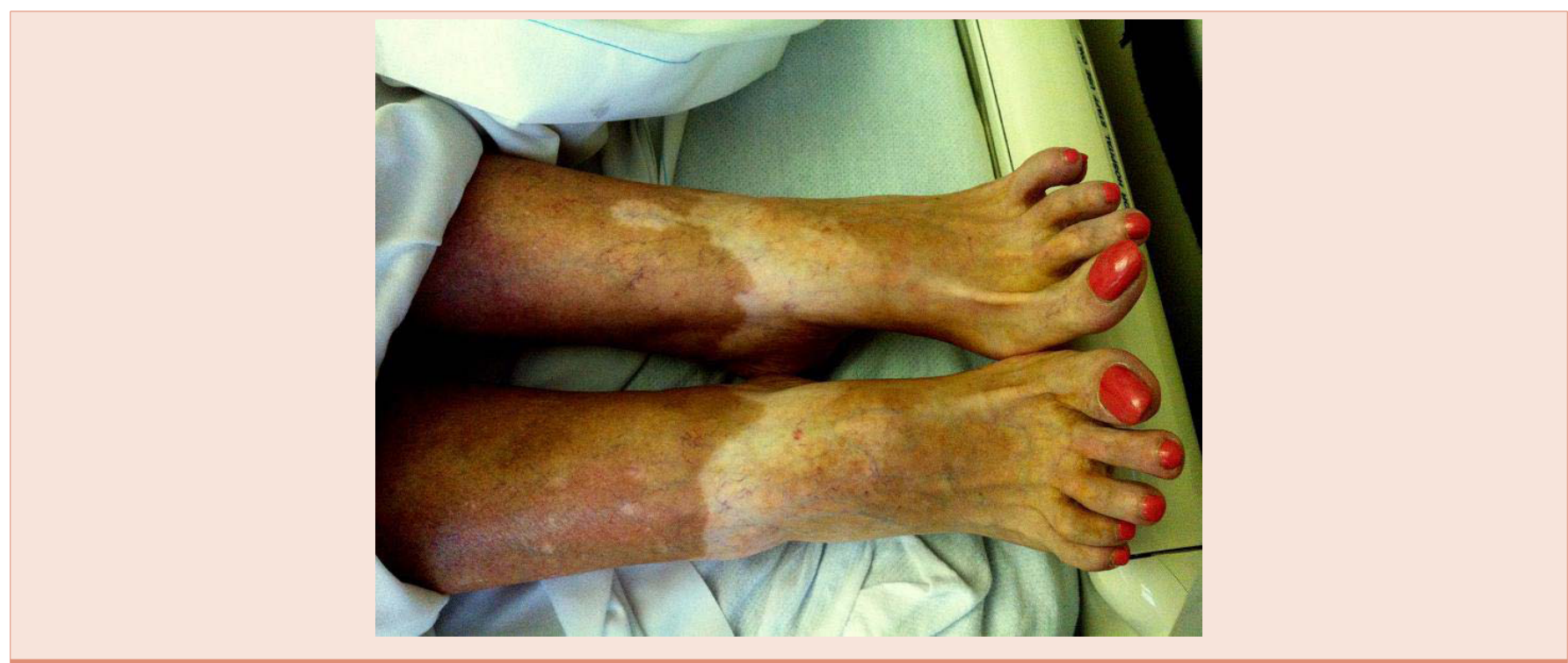

Figure 2: Bilateral skin depigmentation similar to the ones seen in Vitiligo. 